\title{
Juggling between work, studies and motherhood: The role of social support systems for the attainment of work-life balance
}

\begin{tabular}{|c|c|}
\hline \multicolumn{2}{|c|}{$\begin{array}{l}\text { Authors: } \\
\text { Augustine Osei Boakye }{ }^{1,2} \\
\text { Rebecca Dei Mensah" } \\
\text { Magdalene Bartrop-Sackey } \\
\text { Patricia Muah }\end{array}$} \\
\hline \multicolumn{2}{|c|}{$\begin{array}{l}\text { Affiliations: } \\
{ }^{1} \text { Department of Management } \\
\text { and Human Resource, Faculty } \\
\text { of IT Business, Ghana } \\
\text { Communication Technology } \\
\text { University, Takoradi, Ghana }\end{array}$} \\
\hline \multicolumn{2}{|c|}{$\begin{array}{l}{ }^{2} \text { Department of Human } \\
\text { Resource Management, } \\
\text { School of Business, University } \\
\text { of Cape Coast, Cape Coast, } \\
\text { Ghana }\end{array}$} \\
\hline \multicolumn{2}{|c|}{$\begin{array}{l}{ }^{3} \text { School of Business and } \\
\text { Management Studies, Cape } \\
\text { Coast Technical University, } \\
\text { Cape Coast, Ghana }\end{array}$} \\
\hline \multicolumn{2}{|c|}{$\begin{array}{l}{ }^{4} \text { Department of Business } \\
\text { Administration, Faculty of } \\
\text { Business, Heritage Christian } \\
\text { College, Accra, Ghana }\end{array}$} \\
\hline \multicolumn{2}{|c|}{$\begin{array}{l}\text { Corresponding author: } \\
\text { Augustine O. Boakye, } \\
\text { aoboakye@gctu.edu.gh }\end{array}$} \\
\hline \multicolumn{2}{|c|}{$\begin{array}{l}\text { Dates: } \\
\text { Received: } 11 \text { Jan. } 2021 \\
\text { Accepted: } 31 \text { Aug. } 2021 \\
\text { Published: } 19 \text { Oct. } 2021\end{array}$} \\
\hline \multicolumn{2}{|c|}{$\begin{array}{l}\text { How to cite this article: } \\
\text { Osei Boakye, A., Dei Mensah, } \\
\text { R., Bartrop-Sackey, M., \& } \\
\text { Muah, P. (2021). Juggling } \\
\text { between work, studies and } \\
\text { motherhood: The role of } \\
\text { social support systems for } \\
\text { the attainment of work- } \\
\text { life balance. SA Journal of } \\
\text { Human Resource } \\
\text { Management/SA Tydskrif } \\
\text { vir Menslikehulpbronbestuur, } \\
\text { 19(0), a1546. } \\
\text { https://doi.org/10.4102/ } \\
\text { sajhrm.v19i0.1546 }\end{array}$} \\
\hline \multirow{2}{*}{ Read online: } & \\
\hline & $\begin{array}{l}\text { Scan this } Q R \\
\text { code with your } \\
\text { smart phone or } \\
\text { mobile device } \\
\text { to read online. }\end{array}$ \\
\hline
\end{tabular}

Orientation: In recent years, work-life balance has become one of the most important issues of interest to researchers and policymakers. Although women have been identified to be more at risk of work-life imbalance, little is known about the work-life balance pursuits of women who study in addition to their work in non-Western contexts.

Research purpose: Drawing from the ecological system theory and the conservation of resources theory, this study explored the lived experiences of women who study in addition to their work to understand how they achieve work-life balance.

Motivation for the study: The views of working mothers on how they strive to balance their work, studies and motherhood can influence the development and implementation of HR policies that empower women to climb the upper echelon of organisations.

Research approach/design and method: Six respondents knowledgeable on the subject were recruited with snowball sampling and further interviewed.

Main findings: Thematic analysis of the interview transcripts revealed work flexibility, co-worker support, supportive supervisor, supportive family and programmed work-life as the main themes, which explained how working mothers maintained a sense of well-being. Cardinal amongst the themes was the synergistic role of extended family members.

Practical/managerial implications: Organisations are encouraged to develop and implement family-friendly policies that can promote healthy well-being of its workforce whilst facilitating the training and development of women.

Contribution/value-add: This study contributes to work-family literature by providing empirical evidence from a non-Western context as previous research was predominantly conducted in Western contexts.

Keywords: work-life balance; social support system; studying; motherhood; healthy well-being; women empowerment; sustainable development goals.

\section{Introduction}

\section{Orientation}

The issue of work-life balance has received considerable attention across the globe over the last few decades (Barber, Conlin, \& Santuzzi, 2019; De Cieri, Holmes, Abbott, \& Pettit, 2005; Maxwell \& McDougall, 2004). Indeed, work-life balance has been characterised as an important area of human resource management that is of great concern to researchers, governments, management and employee representatives globally (Bateman, Collins, \& Cunningham, 2016; De Cieri et al., 2005). Work-life balance has been identified as a vital feature of a healthy working environment as espoused in the ecological systems theory (Grzywacz \& Marks, 2000). For individuals to experience work-life balance, the ecological systems theory posits that work and non-work microsystems must function together to create a permeable work-life boundary, which is mutually supportive (Haddon, Hede, \& Whiteoak, 2009). Again, for an individual's work and non-work environments to mutually support each other, the conservation of resources theory (COR) maintains that individuals tend to seek, maintain and protect resources that have salient value to them (Hobfoll, 2001). Thus, individuals must rely on resources that abound in their environment to facilitate the achievement of their set goals, whilst reducing stress and stimulating the maintenance of a healthy well-being (Haddon et al., 2009; Hobfoll, 2002). 
The evidence on the relevance of work-life balance to employee well-being and organisational outcome is ubiquitous (Barber et al., 2019; Bobat, Mshololo, \& Reuben, 2012; Igbinomwanhia, Iyayi, \& Iyayi, 2012; Tariq, Aslam, Saddique, \& Tanveer, 2012; Whitehead \& Kotze, 2003). Employees who report being satisfied with their work-life balance pursuits also report high job satisfaction and commitment and lower turnover intention (Bobat et al., 2012; Gomez, Khan, Malik, \& Saif, 2010; Haar, Russo, Suñe, \& Ollier-Malaterre, 2014; Mas-Machuca, Berbegal-Mirabent, \& Alegre, 2016; Shujat, Cheema, \& Bhutto, 2011). Likewise, the correlates of work-life balance and employee physical and psychological health are well established in the literature (Fotiadis, Abdulrahman, \& Spyridou, 2019; Haar et al., 2014; Whitehead \& Kotze, 2003). Similarly, employee's satisfaction with work-life balance significantly impacts their job performance and organisational efficiency and effectiveness (De Villiers \& Kotze, 2003; Dousin, Collins, \& Kler, 2019; Johari, Tan, \& Zukarnain, 2016; Whitehead \& Kotze, 2003). This indicates that any endeavour to investigate on work-life balance cannot be overemphasised as the findings can be highly beneficial to the welfare of individuals and their organisation. More importantly, an exploration on how women maintain healthy well-being whilst juggling across work, studies and motherhood is timely as women have been identified to be at risk when it comes to work-life balance pursuits (Cho et al., 2016; Deshmukh, 2018; Lendák-Kabók, 2020; Whitehead \& Kotze, 2003).

Individuals who combine their work with studying grapple with a range of responsibilities in their personal and professional lives that can affect their maintenance of healthy well-being and often result in work-family conflict (Ruzungunde \& Mjoli, 2020). This is a challenge for working parents as they oversee multiple responsibilities. Particularly, working mothers who fall in this category and are pursuing a university education are envisaged to be at risk of maintaining healthy well-being (Nicklin, Meachon, \& McNall, 2019; Soysa $\&$ Wilcomb, 2015). This is because, education at the university level has been identified to be generally associated with higher levels of stress and lower levels of well-being (Nicklin et al., 2019; Soysa \& Wilcomb, 2015). Consequently, working mothers who study alongside are at higher risk as they will be dealing with competing and compelling responsibilities from work, university and home. Yet, little research has explored how working mothers who are still engaged in post-school education maintain a sense of well-being whilst juggling with work, studies and motherhood. The paucity of research on mothers who study whilst working frustrates the formulation of targeted human resource policy and practice that are based on solid research. Accordingly, the sustainable development goals (SDGs) 4 and 5 that encourage the empowerment of women through quality education will be under threat, particularly for women in paid employment who want to further their education as a means of climbing the upper echelon of their organisation (Odera \& Mulusa, 2020). Therefore, this study also contributes to the ongoing discourse on how SDGs can be harnessed to deepen the empowerment of women across the globe.
The work-life interface can be generally described as intertwined (Chummar, Singh, \& Ezzedeen, 2019; MartínezLeón, Olmedo-Cifuentes, \& Sanchez-Vidal, 2019). This is because, just as work activities can meddle with non-work and personal activities, non-work life can equally interfere in one's job (Martínez-León et al., 2019). A lot of negative consequences arise when people are unsuccessful in achieving work-life balance (Chummar et al., 2019; MartínezLeón et al., 2019), and this can be devastating for women as they perform substantial responsibilities at home. When individuals are unable to balance their work with non-work life, it may result in reduced interaction with family members thereby thwarting the chances of spending quality time with them (Watts, 2009). Likewise, individuals who are unable to attain work-life balance may equally experience poor job performance and organisational performance (De Villiers \& Kotze, 2003). Moreover, when organisational structures require individuals to stay and work long hours as a proof of their commitment and readiness for career development, such organisational demands can adversely affect the nonwork life of such individuals (Marafi, 2013).

For most workers, managing the boundaries between work and non-work life has become deleterious such that the time and energy for personal life and leisure is often constrained (Kinman \& Jones, 2008). The difficulty in attaining a balance between work and non-work life can be traced to changes in workforce demographics with particular attention to the increased dual-earner partnership, increased women in paid employment and blurred gender roles (Annor, 2016; Chung, 2018; O'Donnell, Ruth-Sahd, \& Mayfield, 2019). Accordingly, many research reports contend that women tend to experience more challenges in balancing their work and nonwork life as they now perform economic roles at work in addition to their non-paid socio-cultural roles (Cho et al., 2016; Deshmukh, 2018; Lendák-Kabók, 2020; Whitehead \& Kotze, 2003). Consequently, human resource policies need to evolve if they are to adequately address these pressing challenges amidst contributing to the well-being of employees. This can be done properly when such changes are done based on continuous research that this study intends to provide.

\section{Research purpose and objectives}

The plethora of literature on work-life balance has unequivocally demonstrated its utility to employees' and organisational outcomes, respectively. Although working parents perform numerous roles at work and home, which complicates their chances of successfully experiencing worklife balance, mothers who are studying in addition to their professional work are more at risk. Yet, there exists a dearth of research on how mothers who are studying in addition to their work strive to maintain healthy well-being. As the SDGs aspire to reduce gender inequality whilst empowering women on a global landscape (Odera \& Mulusa, 2020), findings from this study can help intensify such initiatives. Therefore, the purpose of this study is to explore how mothers who are studying in addition to their work strive to 
achieve work-life. Of paramount interest in this study is to also explore their lived experiences and bring to the fore some of the social support systems they harness in their bid to maintain healthy well-being.

\section{Literature review}

The extant literature on work-life balance demonstrates that many employees continue to sacrifice their personal time to balance their work and non-work life (Murthy \& Shastri, 2015). This observation is consistent with the findings of Cho et al. (2016) who also reported that the gendered nature of the workplace coerces women to sacrifice their personal life to work longer hours. Women are particularly noted to experience role conflict in addition to their maternal roles, they play other numerous roles within and outside their workplace (Murthy \& Shastri, 2015; Whitehead \& Kotze, 2003). Admittedly, paternal role stereotypes are evolving with many men now who have reportedly taken up a lot of roles in their household, most of which hitherto were not ascribed men roles (Murthy \& Shastri, 2015). Because of the ever-changing gender role stereotypes, O'Donnell et al. (2019) as well as Chung (2018) maintain that gender roles are becoming blurred, with more women experiencing a lot of challenges in attaining work-life balance (Murthy \& Shastri, 2015; Whitehead \& Kotze, 2003). Other studies have investigated the work-life balance experiences of men and women in mid-life qualitatively (Emslie \& Hunt, 2009). The findings concluded that gender is deeply rooted in the experience of work-life balance with different gender expressing varied responses. Whereas juggling between current multiple roles was observed to be a major source of constraint to women, men confined their discourse of such conflicts to the past when their children were younger (Emslie \& Hunt, 2009). This indicates that even in the absence of children, women continue to experience higher difficulty in achieving work-life balance. In line with the ecological systems theory, women will require more institutional support to successfully maintain healthy well-being. This finding challenges previous results that contend that women with children rather need much institutional support to achieve work-life balance (Smithson \& Stokoe, 2005).

The relationship between boundary management strategies and work-life balance in the Northeast United States has been investigated (Bulger, Matthews, \& Hoffman, 2007). The study showed that work flexibility and personal life permeability were significant predictors of work interference with family life. That is, higher levels of personal life permeability and lower work flexibility were significantly associated with higher levels of work interference with personal life. Likewise, work flexibility and personal life flexibility emerged as the significant predictors of work enhancement of personal life. Thus, higher work enhancement of personal life was significantly associated with higher work flexibility and higher personal life flexibility. These findings were later reaffirmed in similar studies on the instrumental role of work flexibility in the attainment of work-life balance (Chandra, 2012; Kinman \& Jones, 2008). Other studies have also demonstrated that having a partner at home who tends to be supportive can buffer work-life balance (Crowley \& Kolenikov, 2014). In a study on flexible work options and the perception of career harm amongst mothers and other caregivers, the results indicated that women with partners at home reported less stress and less adverse impact on their work unlike women without partners at home (Crowley \& Kolenikov, 2014). It can therefore be deduced that relying on one's supportive spouse is a coping mechanism that people adopt to achieve less stress at home and work. These findings are consistent with the results obtained by Murthy and Shastri (2015) who also saw spousal support and reliance on house helps as an avenue to achieve a satisfying work-life balance. In a recent study, the extent to which differences in working arrangements can impact on work-life balance satisfaction was investigated (Sharkey \& Caska, 2019). The study showed that respondents whose working arrangements involved a combination of working from the office and home emerged being more satisfied with their job and life than their counterparts who worked only from their office. This finding is in line with the previous results obtained by Bulger et al. (2007) so far as work flexibility as an intervention is concerned. This implies that flexible work schedules and telecommuting from home remains a substantial strategy that can be harnessed to improve the work-life balance outcomes of employees.

In another study, the emotional consequences of blurred work-home boundaries on the well-being of working parents were investigated (Matjasko \& Feldman, 2006). The findings of the study indicated that information communication technology (ICT) as a boundary management intervention helped working parents continue their work at home, which increased their intrinsic motivation and helped them to get time for themselves. This ultimately affected their mood and emotions positively. Thus, depending on the nature of the task to be performed, ICT can be used as a boundary management intervention as it can create flexible working opportunities for individuals. Such interventions when properly managed can also nurture positive psychological health amongst employees because, in addition to continuing their work from their preferred location, they get to have a life outside work. The practice of job sharing and job outsourcing has also been identified as an effective strategy to contain work pressures and job overload (Bouwmeester, Atkinson, Noury, \& Ruotsalainen, 2020). Working parents have also been observed to employ active adjustment techniques such as house help, leaving the office on time, planning work schedule in consultation with the spouse, working from home/part-time (Murthy \& Shastri, 2015). Moreover, some working parents coping strategies can be construed as actionoriented strategies, which included the adoption of strict rules to dine together (Murthy \& Shastri, 2015). All these actions were taken to increase the quality of life the working parents had with their family after work. This literature review has demonstrated that the utility of work-life balance to individuals and their organisations is immeasurable. It also elucidates the challenges and the strategies that people adopt 
in their bid to balance their work and family life. The extant literature on the issue of work-life balance has thoroughly explored how it is experienced by both men and women. However, there is a dearth of literature on how working mothers balance their work, studies and motherhood as the literature is predominantly Western in nature (Waterhouse, Hill, \& Hinde, 2017). In addition to women being at a higher risk of experiencing work-life imbalance, the meaning of motherhood and forms of economic activities they participate in are context specific (Waterhouse et al., 2017). Unlike in the Western contexts where motherhood notions tend to be based on biological ties or childbearing, in non-Western contexts, such identities can be achieved through the activity of childrearing by an extended family member (Waterhouse et al., 2017). Likewise, whereas provision exists in Western contexts for the social support of nannies to be acquired in the formal sector, such arrangements are sourced in the informal sector of non-Western contexts via familial referrals (Quisumbing, Hallman, \& Ruel, 2007). Hence, the paucity of research on mothers who combine their professional work with studying in non-Western African contexts frustrates the development of interventions that can target such women (Waterhouse et al., 2017). Therefore, this study intends to fill this literature gap by conducting a study in Ghana. This exploratory study is envisaged to help extend the work-family literature on women in the labour force and ongoing discourse on how SDGs 4 and 5 can be harnessed to empower and improve their well-being.

\section{Research design}

\section{Research approach}

This study adopted the qualitative research approach as the research objectives can be best tackled from a qualitative standpoint. That is, although a lot of studies have been conducted on the phenomenon of work-life balance, the lived experiences on how working mothers balance their work, studies and motherhood is scarcely researched. Guided by social constructionism, this study intends to unravel rich narratives and lived experiences of working mothers who are also studying on the phenomenon of worklife balance (Creswell, 2007).

\section{Research strategy}

The qualitative research method adopted for this study is phenomenology. Phenomenology is a type of qualitative research approach that is used when a researcher wants to reduce several people's experience of a concept or a phenomenon to a description that can be collectively represented (Creswell, 2007; Shi, 2013). In phenomenology, the phenomenologist collects qualitative data from respondents who have experienced a phenomenon to create a composite description that represents the true essence of the experiences for the entire respondents (Creswell, 2007; Shi, 2013). As this study intends to explore and construct a composite description of how mothers who study in addition to their work strive to achieve work-life balance, the phenomenology method becomes suitable.

\section{Research method}

\section{Research setting}

The study was conducted in a research laboratory of the university where the first author works as a Lecturer. This setting was suitable as it afforded the study an uninterruptible and convenient environment. All the respondents were familiar with the research laboratory and this helped them to relax and feel at ease during the interview sessions.

\section{Entrée and establishing researcher roles}

Throughout this research, the authors had to accomplish numerous roles to ensure the success of the study. Firstly, the authors performed the role of a planner by meticulously deciding on issues such as the selection of respondents, data collection and data analysis. As the first author is a lecturer in the university where the study was conducted, he initiated contact with the appropriate authorities and recruited the respondents. Furthermore, the first author played an interviewer role by interviewing all the respondents to share their experiences on how they balance their work, studies and motherhood. The authors played the role of listeners and transcribers after the data collection. Thereafter, the authors performed the role of data analysts by providing a universal essence to various nuanced lived experiences shared by the respondents (Creswell, 2007; Shi, 2013). In all the numerous roles, the authors consciously made efforts not to influence the respondents with their personal opinion (Creswell \& Creswell, 2018).

\section{Research participants and sampling method}

The study is an all-female research as it recruited six working mothers from a tertiary institution in Ghana. All six respondents were married with children and employed in different companies. Respondent 1 was 37 years old and an assistant auditor of her firm. The second respondent was a 36 year old female who worked as a cashier. Respondent 3 was 33 years old and a bank teller. The fourth respondent was a 36 year old female administrator. Respondent 5 was 35 years old and an administrator as well. Finally, respondent 6 was a 30 year old bank teller. The mean age of the six respondents was 35 years. The suitability of this sample for the study is that they constitute individuals who have wealth of experience in balancing their work, studies and motherhood. The respondents for this study were selected using the snowball technique. After one of their lectures, an announcement was made to invite women who are studying in addition to their work for an upcoming research and the first respondent volunteered. After identifying and interviewing the first respondent, she was asked to recommend some of her colleagues in the university who shared similar experiences. The recommendation process was repeated until the authors got to the sixth respondent where no new experiences were emerging as a result of data saturation (Creswell \& Creswell, 2018).

\section{Data collection methods}

The primary data that was used in this study was collected from respondents with the help of a semi-structured 
interview guide. A semi-structured interview guide is a type of guide in which the researcher (interviewer) does not follow a strict and formal list of questions (Kvale, 1996). Rather, in addition to predetermined themes, there is room for the interviewer to ask new questions based on the informant's responses and how events unfold during data collection (Kvale, 1996). An example of the predetermined questions that were on the interview guide is as follows: 'Can you share with me some of the arrangements in your organisation which assist you to balance your work and nonwork (family) life?'.

\section{Data recording}

After obtaining the consent and permission from the participants, all the interview sessions conducted were recorded with an audio device. This assisted the authors to holistically capture all the conversations that ensued during the interview process. Thereafter, all the recorded interviews were played back and transcribed word-for-word.

\section{Strategies employed to ensure data quality and integrity}

To ensure the quality and integrity of the data, Lincoln and Guba's criteria for quality in qualitative research was strictly adhered to (Korstjens \& Moser, 2018; Lincoln \& Guba, 1985). The four criteria include credibility, transferability, dependability and confirmability, and together they demonstrate the trustworthiness of qualitative research findings. Credibility was ensured in this study by reporting exactly what the respondents said and this was amplified with illustrative quotes. To ensure transferability, the authors synthesised the thick descriptions of the various individuals into phrases that have a universal essence (Creswell, 2007; Shi, 2013) and this can be generalised to other respondents with similar experiences (Korstjens \& Moser, 2018). Dependability was ensured in the study by meticulously planning and recording all the phases of the research process as qualitative research standards dictates (Korstjens \& Moser, 2018). Confirmability was achieved in this study by ensuring that all the interpretations given are grounded in the data but not a reflection of the authors' viewpoints (Korstjens \& Moser, 2018).

\section{Ethical considerations}

The study adhered to three ethical considerations as suggested by Welman, Kruger and Mitchell (2005), and these include informed consent, right of privacy and protection from harm. Firstly, informed consent was read out to the respondents to communicate the purpose of the study after which they were made to sign to signify their consent and permission. Secondly, to ensure the right of their privacy is secured, the respondents were assured that the data collected was for academic purpose only and under no circumstance will their identity be revealed. Accordingly, their names were replaced with pseudonyms (eg., respondent 1, respondent 2, etc.) to hide their identities. Finally, protection from harm was maintained throughout the study by ensuring that the respondents are not subjected to any physical, emotional and psychological harm. The respondents were further informed about their liberty to opt-out of the study at any point if they feel uncomfortable.

\section{Data analysis}

All the interviews recorded were immediately transcribed word-for-word. The authors read over the transcripts several times to become immersed in the data. Afterwards, the authors began the data analysis using the thematic analysis procedure (TAP). The TAP is a method of qualitative data analysis that attempts to identify, analyse and report patterns or themes in a given data set (Braun \& Clarke, 2006). To do this, the researchers followed Pratt, Rockmann and Kaufmann (2006) pattern by utilising their three major steps. The first step involved the use of first-order codes to create provisional categories and this triggered the data reduction process where we used open coding (Pratt et al., 2006). Open coding is a process of analysing the textual content of an interview transcript to create a word or phrase that provides a salient but summative attribute of the text (Akanji, Mordi, Simpson, Adisa, \& Oruh, 2020). In the second step, the researchers consolidated the first-order codes to create conceptual categories as many of them converged at some point. In the third or final step, the researchers consolidated the conceptual categories into themes as a way of generating explanations for how mothers who are studying in addition to their work strive to achieve work-life balance.

\section{Reporting style}

The study presented the various themes that emerged from the data analysis and supported each theme with illustrative quotations. Moreover, the discussion of the themes was interspersed with existing literature to provide a connection to the ongoing discourse on work-life balance.

\section{Findings and discussion}

The main objective of this study was to explore how mothers who are studying in addition to their work strive to achieve work-life balance. Of paramount interest in this study is to also explore their lived experiences and bring to the fore some of the social support systems they harness in their bid to maintain healthy well-being. From the data analysis, five main themes emerged to explain the lived experiences of working mothers. In some instances, some of the themes were further broken into subthemes to elaborate on their nuances. These themes are work flexibility, co-worker support, supportive supervisor, supportive family, programmed work-life schedule and challenges in work-life balance. These themes with illustrative quotes from the respondents are as elucidated in-turns in the following section.

\section{Work flexibility}

When respondents were asked on how they strive to achieve work-life balance despite the multiple roles they play across 
different domains, several themes emerged. The first theme that emerged from the data analysis was work flexibility. Some of the respondents opined that the relaxed operational procedures in their organisations granted them the opportunity to attend to personal errands, which contributed towards their work-life balance pursuits:

'There is this kind of flexibility at my workplace. You can actually leave the office for some time to do your personal errands when the place is less busy. Let's say within 1 or $2 \mathrm{~h}$ without any problems. I sometimes use those hours to go to the market to buy some foodstuffs for home. Sometimes too, I use that time to go for parents-teachers association (PTA) meetings.' (Respondent 1, assistant auditor, female, 37 years)

Another respondent indicated that the flexible time for reporting, breaks and closing from work granted the opportunity to balance their work with non-work life:

'After resuming from my 3 months of maternity leave, I was granted $2 \mathrm{~h}$ of free time for breastfeeding. The demarcation and usage of that $2 \mathrm{~h}$ depended on me. This gives me ample time to cater for the child before I come to work. It has reduced the pressure and stress on me to get to the office early.' (Respondent 5 , administrator, female, 35 years)

Moreover, another respondent opined that the flexible working procedures and relaxed protocols in her organisation enabled her to continually breastfeed and bond with her baby:

'I wanted to send my baby to school after 3 months but my manager said it was not a good idea. So they asked me to bring the baby along with the baby's court covered with a mosquito's net to a room in our workplace. After breastfeeding him in the morning, I put him to sleep in the baby's court then go ahead to the banking hall. There are some mobile bankers around so when the baby wakes up, they will go and take care of him for me to finish serving the customers. When the place is less busy, then I will go and take care of him. These arrangements assisted me to take care of the child despite being at work.' (Respondent 6, bank teller, female, 30 years)

This indicates that the flexible and accommodating nature of the respondent's work assisted her to continue bonding with the child whilst performing her responsibilities at work. These preceding results are consistent with earlier findings by Bulger et al. (2007) and Kinman and Jones (2008) as reported in the literature that individuals who experience greater control over their work as a result of flexible work arrangements also report a substantial amount of work-life balance. Likewise, the findings corroborate the earlier results obtained by Chandra (2012) who saw work flexibility as a strategy for achieving worklife balance.

\section{Co-worker support}

Co-worker support, which manifested in sub-themes like support from peers, teamwork and being there for each other in times of need, played an instrumental role in the work-life balance pursuit of the respondents. These found expression in the narratives of the respondent as shown below:
'Whenever my child is sick, my colleagues are always ready to give me all the necessary support. In that case, I can also go and take care of my child whilst somebody steps in for me.' (Respondent 1, assistant auditor, female, 37 years)

In different parlance, another respondent projected the same idea by narrating this:

'The staff over there are sociable and we are all united. There is one lady in my office I trained to do the cash-in so that when I am not around, she can help me. In my absence, they receive the payments on my behalf so that on my return, I will key in the vouchers and balance my cash.' (Respondent 6, bank teller, female, 30 years)

Furthermore, a different respondent contributed to the preceding discourse by indicating that:

'Some of my peers understand my situation as a working parent so they support in that regard with tasks in the office from time to time and this ease the work pressure.' (Respondent 5, administrator, female, 35 years)

The sense of togetherness and working as a team can therefore be construed as a mechanism that eased task difficulty whilst expediting the pace with which respondents completed their work. Consequently, some of the respondents were able to finish their work schedule on time and this enabled them to perform other non-work activities at home and in the university. These findings are in line with the earlier results obtained by Bouwmeester et al. (2020), which reported employees who practice job sharing with colleagues in demanding times experience higher work-life satisfaction. Again, the findings are consistent with the basic tenets of the ecological systems theory that postulates that to attain a healthy well-being, individuals must rely on resources in their environment.

\section{Supportive supervisor}

Supervisory support also emerged as another theme that explained the work-life balance pursuits of the respondents in this study. As epitomised in the quotations below, some of the respondents espoused that the empathy and assistance they received from their supervisors/manager enhanced the quality of life they experienced:

'Our supervisor organized periodic workshops for us to keep us abreast with best practices. He taught us how to get more customers. Because if you don't have the rapport and customer relation skill, it will be difficult to get them. This increased my confidence and control over the job and that is why I was able to combine it with my studies.' (Respondent 2, cashier, female, 36 years)

Other respondents also shared similar views so far as supervisory support in the achievement of work-life balance is concerned:

'My baby was delivered prematurely so the 3 months maternity was not going to be enough. After discussing it with my manager, he supported me by extending my leave from 3 to 6 months. I would say it was really helpful since my baby still had some 
health complications even after 6 months. So I don't know how I would have taken care of my baby and home with the 3 months leave.' (Respondent 3, bank teller, female, 33 years)

This was further corroborated by respondents who indicated that:

'When I was pregnant, my manager was doing a whole lot of things for me. Sometimes I show up at work very weak and he asks me to go home and rest. He will then go into my teller cage and do all my transactions for me.' (Respondent 6, bank teller, female, 30 years)

These results posit supervisory support as very much pivotal in the attainment of healthy well-being. The findings are consistent with earlier reports by Bateman et al. (2016) who found that in organisations where supervisors offer career breaks like maternity leave, employee satisfaction with work-life balance tends to be high. In the same vein, the findings confirm the core argument of the ecological systems theory, which postulates individual's reliance on resources in their environment.

\section{Supportive family}

As a source of social support system, the family emerged as ever important for the achievement of work-life balance in this study. Indeed, all the respondents provided narratives that portrayed the synergistic role family members played to enhance the quality of life they experience. For instance, respondent 1 opined that:

'My husband has been very supportive in all my endeavours. As soon as my kids wake up in the morning, he will not even call me. He will bath them, dress and take care of them whilst I am at the kitchen working. Again, whenever he sees me learning, he will tell all the kids to go inside and sleep because mummy is learning. He will engage them with something that will distract them. This has reduced my level of stress. Most of the things that I am supposed to do has been cut off so I always go to the office fully relaxed and not stressed from the outset.' (Respondent 1 , assistant auditor, female, 37 years)

Other respondents further provided accounts that predominantly projected the support they received from their husbands:

'My husband has been very supportive. When it comes to washing, because he knows I am attending a university and working at the same time, he sometimes washes with me at dawn. Other times too, he grants me the liberty to attend to my studies whilst he washes in order not to be tired. Occasionally, he does the sweeping and a whole lot of things just to lessen my workload and I am so much grateful for that.' (Respondent 6, bank teller, female, 30 years)

These findings are in support of the results obtained by Crowley and Kolenikov (2014) as well as Murthy and Shastri (2015) who reported that a supportive spouse at home can act as a buffer for the attainment of work-life balance. Consistent with the ecological systems theory, these findings demonstrate that the support the respondents received from their nuclear family members allowed them to be successful not only at home but at work and in the university as well. Thus, it helped in reducing the stress on them whilst saving their energy and concentration for other domains. It is worth noting that unlike the reports in the literature that predominantly centred on the support from the nuclear family members, this present study found that the extended family members continue to play a huge role in the attainment of work-life balance. Below are quotations from some respondents to that effect:

'When I wake up on weekends, all that I do is to instruct the children to brush their teeth. Then I also take my bath and go to school. The remaining task in the house will be handled by my mother except for cooking. So she helps me a lot. Also, when there is an occasion at work which will extend my closing time, it is my mother who takes care of the kids till I return.' (Respondent 1, assistant auditor, female, 37 years)

Likewise, other respondents provided narratives to suggest that the support they receive from other extended family members accounted for the feet they achieve in balancing their work with non-work activities:

'When I am going for lectures on weekends, I take my child along and leave her with my junior sister who has a grocery shop in town. After my classes for the day, then I will go for my child so that we will all return home.' (Respondent 3, bank teller, female, 33 years)

Another respondent re-echoed the preceding narrative by saying that:

'I am staying with my mother-in-law so some of the responsibilities are taken over by her. After taking the kids to school in the morning, I just go to my workplace. By the time the kids return too, I will be at work so my in-law will take care of them until I return to take over. She helps them to do their homework, prepares lunch and supper for them too while I concentrate on my work in the office.' (Respondent 4, administrator, female, 36 years)

These accounts indicate that the extended family support system assisted the respondents in diverse ways towards the achievement of work-life balance, without which life would have been unbearable for them. These findings are not surprising as Ghana is considered a collectivistic context and extended family members continue to play key roles in the upbringing of children (Quisumbing et al., 2007; Waterhouse et al., 2017). In the narration of one of the respondents, househelp emerged to play a pivotal role in the achievement of work-life balance. That is, a house-help (house-girl) who had become a member of the respondent's family because of her long stay supported the respondent to juggle across work, university and family responsibilities. This can be inferred from the response from the participant below:

'I have a girl who is assisting me as my house-help. So, what she does is wash the baby's clothes whilst I prepare the baby's food and send him to school in the morning. Then the house-help will also go to school. But when she comes back from school, she stays with me at my workplace. Usually, around 4 o'clock, they will bring the baby to me at the office. Then the house-help will take care of the baby since I do not close early. Whilst she is 
taking care of the baby, I also continue with my office work. Sometimes too, I ask her to prepare something so that when we go home in the evening we can eat. Because of the baby, I do not want to eat outside.' (Respondent 6, bank teller, female, 30 years)

This report from the respondent indicates that without the house-girls assistance, combining work, studies and home responsibilities would have been a herculean task. This is because the house-girl assists the respondent in performing home chores as well as attending to the baby even at her workplace. This finding supports the previous results in the literature that posits that some working parents indulge in the assistance of house helps to assist in balancing their work with family life (Matjasko \& Feldman, 2006). But unlike the participants in Matjasko and Feldmen (2006) who were only working parents, this present study was conducted with working mothers who were studying alongside, and this extends the literature. Furthermore, the preceding result corroborates Quisumbing et al.'s (2007) finding that in nonWestern contexts, social support for motherhood can be secured from the informal sector.

\section{Programmed work-life schedule}

The last theme that emerged out of the data analysis is a programmed work-life schedule. By programmed work-life schedule, I am referring to the degree to which a trajectory can be deciphered from people's daily work-life schedule. This is manifested when individuals in an attempt to narrate their lived experiences consciously or unconsciously project such as calculated work-life management. The theme of programmed work-life schedule can be illustrated by the response given by the participant below:

'I am an assistant auditor and most of the time, our works are not all that difficult. It involves checking on the transactions of field officers and operational officers. Usually, when it is getting to the end of the month, I go through stress a lot and leave the office very late. But in the first 2 weeks of the month, I don't do much work. I take that opportunity to go through my university reading resources that I have not covered during those 2 weeks so that when we enter the third week and I am busy, it will not affect my studies.' (Respondent 1, assistant auditor, female, 37 years)

This indicates that in their bid to adjust fluctuations in work pressures with studies and motherhood, some of the respondents adopt a programmed work-life pattern, which is followed to the latter. In a similar vein, the theme of programmed work-life schedule resonated in feedback from another respondent, which is presented below:

'I live my life in such a way that weekends are always reserved for my personal studies. It is only after my lectures or when a class does not come on that I squeeze other things there. My weekends are always packed with my academic activities, so I am unable to attend to my work and family needs. This Saturday for instance I closed early from lectures so I can do something which is not academic-related. I will just call my husband to verify if he would like me to prepare something for him in the evening, then I will just send the house-help to buy the foodstuffs.' (Respondent 6, bank teller, female, 30 years)
The preceding narration further re-affirms the notion that, in an attempt to overcome the pressures associated with work, studies and motherhood, some of the respondents consciously programme their activities along their work-life interface. Consequently, juggling between work, studies and motherhood, which can be perceived as a herculean task, is successfully managed by these respondents. These findings support Murthy and Shastri's (2015) notion of active adjustment techniques, which posits that although the creation of family friendly work atmosphere is a good initiative to achieve work-life balance, the individual must take charge and personally tailor these initiatives for their well-being.

\section{Practical implications}

The study has implications for organisational and managerial practice. Organisations and managers are encouraged to develop and implement family friendly policies that facilitate the attainment of work flexibility, coworker support and supervisory support as such policies were noted to promote the healthy well-being of mothers who are studying in addition to their professional life. Likewise, considering the peculiar challenges that mothers who are studying in addition to their work face, training and development opportunities should flexibly target them in order not to exclude them from such an empowerment drive. Such programmes can equally remind them of the need to harness the extended family support system to augment the formal ones they receive from work as it was proven to be helpful in the study. It is believed that when governments and other gender advocates push for the formulation and implementation of family friendly policies at work, it will empower and improve the well-being of working mothers and their dependents that will ultimately facilitate the attainment of SDGs 4 and 5 .

\section{Limitations and recommendations}

Although the findings of this study are encouraging, there are some limitations that are worth noting. The use of only six respondents makes it difficult to generalise the findings to a larger population. Future research can replicate this study with a larger sample size to verify if different results are likely. Again, the study had all-female participants, and this makes the findings more relevant to women and female advocates. However, emerging research demonstrates that men equally experience a great deal of difficulty in achieving work-life balance. Consequently, gender analysis researchers can improve the study in the future by considering both men and women.

\section{Conclusion}

Drawing from the ecological systems theory and the COR, the present research explored the views of working mothers to verify how they balance their work, studies and motherhood. It is evident from the research findings that the amount of work flexibility, supervisory support and coworker support the working mothers experience on their job contributed immensely to their work-life balance. This was 
strongly anchored on the familial support they received without which their well-being would have been deplorable. The authors believe that by developing and implementing family friendly human resource policies that target working women who aspire to empower themselves through university education, the well-being of women in general and their organisation can mutually improve.

\section{Acknowledgements Competing interests}

The authors declared that there exist no competing interests.

\section{Author's contributions}

The original manuscript was formulated by A. O. B., and it was further refined to a publishable standard with the help of M. B. S. and P. M. under the close supervision and scrutiny of R. D. M.

\section{Funding information}

The study did not receive a research grant from any funding agency in the public, commercial or non-profit sector.

\section{Data availability}

The data used for this study has been stored and can be made available upon request.

\section{Disclaimer}

The views and opinions expressed in this article are those of the authors and do not necessarily reflect the official policy or position of any affiliated institution of the authors.

\section{References}

Akanji, B., Mordi, C., Simpson, R., Adisa, T.A., \& Oruh, E.S. (2020). Time biases: Exploring the work-life balance of single Nigerian managers and professionals. Journal of

Annor, F. (2016). Work-family conflict: A synthesis of the research from cross-national perspective. Journal of Social Sciences, 12(1), 1-13. https://doi.org/10.3844/ jssp.2016.1.13

Barber, L.K., Conlin, A.L., \& Santuzzi, A.M. (2019). Workplace telepressure and worklife balance outcomes: The role of work recovery experiences. Stress and Health 35(3), 350-362. https://doi.org/10.1002/smi.2864

Bateman, L.E., Collins, J.M., \& Cunningham, S.J. (2016). A qualitative study of work-life balance amongst specialist orthodontists in the United Kingdom. Journal of Orthodontics, 43(4), 288-299. https://doi.org/10.1080/14653125.2016.1229846

Bobat, S., Mshololo, N., \& Reuben, S. (2012). A qualitative exploration of women's worklife balance over the life course: A case study of retail managers. Journal of Psychology in Africa, 22(2), 227-232. https://doi.org/10.1080/14330237.2012.1082052

Bouwmeester, O., Atkinson, R., Noury, L., \& Ruotsalainen, R. (2020). Work-life balance policies in high performance organisations: A comparative interview study with millennials in Dutch consultancies. German Journal of Human Resource Management, 35(2), 6-32. https://doi.org/10.1177/2397002220952738

Braun, V., \& Clarke, V. (2006). Using thematic analysis in psychology. Qualitative Research in Psychology, 3(2), 77-101. https://doi.org/10.1191/1478088706qp063oa

Bulger, C.A., Matthews, R.A., \& Hoffman, M.E. (2007). Work and personal life boundary management: Boundary strength, work/personal life balance, and the segmentation-integration continuum. Journal of Occupational Health Psychology, 12(4), 365-375. https://doi.org/10.1037/1076-8998.12.4.365

Chandra, V. (2012). Work-life balance: Eastern and western perspectives. International Journal of Human Resource Management, 23(5), 1040-1056. https://doi.org/10.1 080/09585192.2012.651339

Cho, Y., Park, J., Ju, B., Han, S.J., Moon, H., Park, S., ... Park, E. (2016). Women leaders' work-life imbalance in South Korean companies: A collaborative qualitative study. Human Resource Development Quarterly, 27(4), 461-487. https://doi. org/10.1002/hrdq.21262
Chummar, S., Singh, P., \& Ezzedeen, S.R. (2019). Exploring the differential impact of work passion on life satisfaction and job performance via the work-family interface. Personnel Review, 48(5), 1100-1119. https://doi.org/10.1108/PR-02interface. $2017-0033$

Chung, H. (2018). Dualization and the access to occupational family-friendly workingtime arrangements across Europe. Social Policy \& Administration, 52(2), 491-507. https://doi.org/https://doi.org/10.1111/spol.12379

Creswell, J. W. (2007). Qualitative inquiry and research design: Choosing among five approaches (2nd ed.). London: Sage Publications.

Creswell, J.W., \& Creswell, J.D. (2018). Research design: Qualitative, quantitative, and mixed methods approaches (5th ed.). Thousand Oaks, CA: Sage.

Crowley, J.E., \& Kolenikov, S. (2014). Flexible work options and mothers' perceptions of career harm. The Sociological Quarterly, 55(1), 168-195. https://doi. org/10.1111/tsq.12050

De Cieri, H., Holmes, B., Abbott, J., \& Pettit, T. (2005). Achievements and challenges for work/life balance strategies in Australian organizations. International Journal of Human Resource Management, 16(1), 90-103. https://doi.org/10.1080/ of Human Resource Man

Deshmukh, K. (2018). Work-life balance study focused on working women. International Journal of Engineering Technologies and Management Research, 5(5), 134-145. https://doi.org/10.29121/ijetmr.v5.i5.2018.236

De Villiers, J., \& Kotze, E. (2003). Work-life balance: A study in the petroleum industry. SA Journal of Human Resource Management, 2(1), 15-23. https://doi. org/10.4102/sajhrm.v1i3.27

Dousin, O., Collins, N., \& Kler, B.K. (2019). Work-life balance, employee job performance and satisfaction among doctors and nurses in Malaysia. Internationa Journal of Human Resource Studies, 9(4), 306. https://doi.org/10.5296/ijhrs. v9i4.15697

Emslie, C., \& Hunt, K. (2009). 'Live to work' or 'work to live': A qualitative study of gender and work-life balance among men and women in mid-life - Emslie-2008 - Gender, work \& organization - Wiley online library. Gender, Work and Organization, 16(1), 151-172. https://doi.org/10.1111/j.1468-0432.2008.00434.x

Fotiadis, A., Abdulrahman, K., \& Spyridou, A. (2019). The mediating roles of psychological autonomy, competence and relatedness on work-life balance and well-being. Frontiers in Psychology, 10(May), 1-7. https://doi.org/10.3389/ fpsyg.2019.01267

Gomez, S.F., Khan, N., Malik, M., \& Saif, M. (2010). Empirically testing the relationship of social support, job satisfaction and work-family balance in Pakistani socio cultural set-up. International Journal of Sustainable Development, 2(1), 51-57.

Grzywacz, J.G., \& Marks, N.F. (2000). Reconceptualizing the work-family interface: An ecological perspective on the correlates of positive and negative spillover between work and family. Journal of Occupational Health Psychology, 5(1), 111-126. https://doi.org/10.1037/1076-8998.5.1.111

Haar, J.M., Russo, M., Suñe, A., \& Ollier-Malaterre, A. (2014). Outcomes of work-life balance on job satisfaction, life satisfaction and mental health: A study across seven cultures. Journal of Vocational Behavior, 85(3), 361-373. https://doi. org/10.1016/j.jvb.2014.08.010

Haddon, B., Hede, A., \& Whiteoak, J.W. (2009). Work-life balance: Towards an integrated conceptual framework. NZ Journal of Human Resources Management, $9(3), 174-186$.

Hobfoll, S.E. (2001). The influence of culture, community, and the nested-self in the stress process: Advancing conservation of resources theory. Applied Psychology: An International Review, 50(3), 337-370. https://doi.org/10.1111/ 1464-0597.00062

Hobfoll, S.E. (2002). Social and psychological resources and adaptation. Review of General Psychology, 6(4), 307-324. https://doi.org/10.1037/1089-2680.6.4.307

Igbinomwanhia, O., Iyayi, O., \& Iyayi, F. (2012). Employee work-life balance as an HR imperative. African Research Review, 6(3), 109-126. https://doi.org/10.4314/ afrrev.v6i3.8

Johari, J., Tan, F.Y., \& Zukarnain, Z.I.T. (2016). Autonomy, workload, worklife balance and job performance teachers. International Journal for Researcher Development, $7(1), 63-83$.

Kinman, G., \& Jones, F. (2008). A life beyond work? job demands, work-life balance, and wellbeing in UK Academics. Journal of Human Behavior in the Socia Environment, 17(1-2), 41-60. https://doi.org/10.1080/10911350802165478

Korstjens, I., \& Moser, A. (2018). Series: Practical guidance to qualitative research. Part 4: Trustworthiness and publishing. European Journal of General Practice, 24(1), 120-124. https://doi.org/10.1080/13814788.2017.1375092

Kvale, S. (1996). Interviews: An introduction to qualitative research interviewing. Thousand Oaks, CA: Sage.

Lendák-Kabók, K. (2020). Women's work-life balance strategies in academia. Journal of Family Studies, O(0), 1-19. https://doi.org/10.1080/13229400.2020.1802324

Lincoln, Y.S., \& Guba, E.G. (1985). Naturalistic inquiry. Thousand Oaks, CA: Sage. https://books.google.com.gh/books?id=2oA9aWINeooC

Marafi, H. (2013). Perception of work life balance - An investigation of education sector of east and west. Asian Journal of Business and Management, 5, 174-180. https://doi.org/10.19026/ajbm.5.5826

Martínez-León, I.M., Olmedo-Cifuentes, I., \& Sanchez-Vidal, M.E. (2019). Relationship between availability of WLB practices and financial results. Personnel Review, 48(4), 935-956. https://doi.org/10.1108/PR-12-2017-0402

Mas-Machuca, M., Berbegal-Mirabent, J., \& Alegre, I. (2016). Work-life balance and its relationship with organizational pride and job satisfaction. Journal of Managerial Psychology, 31(2), 586-602. https://doi.org/10.1108/JMP-09-20140272 
Matjasko, J.L., \& Feldman, A.F. (2006). Bringing work home: The emotional experience of mothers and fathers. Journal of Family Psychology, 20(1), 47-55. https://doi. org/10.1037/0893-3200.20.1.47

Maxwell, G.A., \& McDougall, M. (2004). Work-life balance: Exploring the connections between levels of influence in the UK public sector. Public Management Review, 6(3), 377-393. https://doi.org/10.1080/1471903042000256547

Murthy, M.N., \& Shastri, S. (2015). A qualitative study on work life balance of employees working in private sectior. International Journal of Recent Scientific Research, 6(7), 5160-5167.

Nicklin, J.M., Meachon, E.J., \& McNall, L.A. (2019). Balancing work, school, and personal life among graduate students: A positive psychology approach. Applied Research in Quality of Life, 14(5), 1265-1286. https://doi.org/10.1007/s11482 018-9650-z

O'Donnell, M., Ruth-Sahd, L.A., \& Mayfield, C.O. (2019). An expanded holistic mode of healthy workplace practices. International Journal of Organizational Analysis, 27(5), 1542-1561. https://doi.org/10.1108/ijoa-02-2019-1647

Odera, J.A., \& Mulusa, J. (2020). SDGs, gender equality and women's empowerment: What prospects for delivery? In M. Kaltenborn, M. Krajewski, \& H. Kuhn (Eds.), Sustainable development goals and human rights (pp. 95-118). Cham: Springer International Publishing.

Pratt, M.G., Rockmann, K.W., \& Kaufmann, J.B. (2006). Constructing professional identity: The role of work and identity learning cycles in the customization of identity among medical residents. The Academy of Management Journal, 49(2), 235-262. Retrieved from http://www.jstor.org/stable/20159762

Quisumbing, A.R., Hallman, K., \& Ruel, M.T. (2007). Maquiladoras and market mamas: Women's work and childcare in Guatemala City and Accra. Journal of Development Studies, 43(3), 420-455. https://doi.org/10.1080/00220380701204380

Ruzungunde, V.S., \& Mjoli, T. (2020). An exploration into the role of personality on the experiences of work-family conflict among the mining industry personnel in South Africa. Acta Commercii, 20(1), 1-11. https://doi.org/10.4102/ac.v20i1.774
Sharkey, J., \& Caska, B. (2019). Work-life balance versus work-life merge : Rationale for Research. DBS Business Review, 03, 49-72.

Shi, Z. (2013). Dilemmas in using phenomenology to investigate elementary school children learning English as a second language. Education, 17(1), 3-13. https:// doi.org/10.37119/ojs2011.v17i1.88

Shujat, S., Cheema, F.-E.-A., \& Bhutto, F. (2011). Impact of work life balance on employee job satisfaction in private banking sector of Karachi. IBT Journal of Business Studies (JBS), 7(2), 2-7. https://doi.org/10.46745/ilma.jbs.2011.07.02.02

Smithson, J., \& Stokoe, E.H. (2005). Discourses of work-life balance: Negotiating 'genderblind' terms in organizations. Gender, Work and Organization, 12(2), 147-168. https://doi.org/10.1111/j.1468-0432.2005.00267.x

Soysa, C.K., \& Wilcomb, C.J. (2015). Mindfulness, self-compassion, self-efficacy, and gender as predictors of depression, anxiety, stress, and well-being. Mindfulness, 6(2), 217-226. https://doi.org/10.1007/s12671-013-0247-1

Tariq, A., Aslam, H.D., Saddique, A., \& Tanveer, A. (2012). Work-life balance as a best practice model of human resource management: A win-win situational tool for the employees and organizations. Mediterranean Journal of Social Sciences, 3(1) 557-585. https://doi.org/10.5901/mjss.2012.03.01.577

Waterhouse, P., Hill, A.G., \& Hinde, A. (2017). Combining work and child care: The experiences of mothers in Accra, Ghana. Development Southern Africa, 34(6), 771-786. https://doi.org/10.1080/0376835X.2017.1323627

Watts, J.H. (2009). 'Allowed into a man's world' meanings of work-life balance: Perspectives of women civil engineers as 'minority' workers in construction. Gender, Work and Organization, 16(1), 37-57. https://doi.org/10.1111/j.14680432.2007.00352.x

Welman, J. C., Kruger, F., Mitchell, B., \& Huysamen, G. K. (2005). Research methodology. Cape Town: Oxford University Press.

Whitehead, T., \& Kotze, M.E. (2003). Career and life-balance of professional women A South African study. SA Journal of Human Resource Management, 2(1), 77-84. https://doi.org/10.4102/sajhrm.v1i3.19 